\title{
Integrated Development Plans without Development Indicators: Results from Capricorn District Municipalities in South Africa
}

\author{
Human M Mautjana \\ University of Limpopo, Tufloop Graduate School of Leadership \\ Republic of South Africa \\ Oliver Mtapuri \\ University of Limpopo, Tufloop Graduate School of Leadership \\ Republic of South Africa \\ Email address: simbaomtapuri@yahoo.com
}

\section{Doi:10.5901/mjss.2014.v5n8p474}

\section{Abstract}

The use of development indicators in the Integrated Development Planning (IDP) process of municipalities is not only a legislative requirement but also ensures that municipalities effectively assess the impact of their development programmes and projects on the objectives of sustainable development. Central to the constitutional mandate, is the Municipal Systems Act of 2000, which details the general matters pertaining to IDPS. Development indicators provide municipalities, as the main implementing agencies for government policies and programmes, a framework to present aggregated data on human development and provide evidence-based pointers to the evolution of society. A properly constructed set of indicators may not only suggest the planning measures which should be employed but also throw light on a better formulation of targets, goals and objectives of planning. Based on secondary research, interviews were held with gatekeepers and a questionnaire for other stakeholders. This paper explores the limited use of these development indicators in the IDPs of local municipalities. It shows that municipalities have little understanding on development indicators and how they can help them in addressing challenges experienced by communities. The development of a compendium of development indicators by local government and the inclusion of those indicators in strategic documents of municipalities must be mandatory. The major contribution of this article is the model for data collection and processing for municipalities which it posits and consists of a step by step procedure from data collection, single to composite indicators generation to assessment and interpretation of data and results including monitoring and evaluation. The efficiency of the use of development indicators for planning may not be fully realized because of the manner in which municipal planners have been found to employ indicators for their own purpose.

Keywords: Development indicators, Integrated Development Plan, effectiveness

\section{Introduction}

Service delivery in South Africa is of crucial importance because of the central role it can play in poverty alleviation. According to Krige (1998), the South African local authorities were historically not economically viable and that the level of service delivery, particularly in townships, was inexcusable. The introduction of integrated development planning by the Department Cooperative Governance, Human Settlement and Traditional Affairs (CoGHSTA) was an attempt to improve the planning process and enhance service delivery at the municipal level. The Integrated Development Plan (IDP) is at the core of South Africa's post-apartheid municipal planning system and is regarded as a key instrument in an evolving framework of intergovernmental planning and coordination. The introduction of the IDP was a response to challenges facing the post-apartheid government and the need to speed up service delivery for a better life for all. It is primarily a plan concerned with directing and coordinating the activities of an elected municipal authority.

The 1998 White Paper on Local Government (hereafter, White Paper) identified the IDP as a key tool of local government which is concerned with promoting the economic and social development of communities. Linked to the IDP is a broader package of instruments which include performance management tools, participatory processes and propositions on service delivery partnerships. The White Paper emphasizes the role of the IDP in providing a long-term vision for a municipality, setting out the priorities of an elected council, linking and coordinating sectoral plans and strategies, aligning financial and human resources with implementation needs, strengthening the focus on environmental 
sustainability and providing the basis for annual and medium-term budgeting. The purpose of Integrated Development Planning is to provide a framework within which municipalities can be coordinated, based on the understanding of their own situation (RSA, 1998).

Municipalities across the country prepare IDPs which are supposed to improve the living conditions of the people. However, the planning process does not identify measurable indicators, thus making it difficult if not impossible to determine the success levels of an IDP and its effectiveness. It is therefore against this background that this article investigates measurable indicators which should exist within the IDP as baseline and benchmark indicators in order to assess progress being made by the municipality and obviate service delivery protests which have since become the order of the day. In the context of this study, development indicators refer to information that allows organisations to measure progress in an effort to eradicate poverty.

The aim of this article is to provide information on development indicators in ensuring the effectiveness of IDPs with the overarching objective of investigating the existence of and gaps within current development indicators in four local municipalities in the Capricorn District Municipality, namely, Aganang, Molemole, Polokwane and Lepelle-Nkumpi in Limpopo South Africa

\section{Literature Review}

Kriege (1998) highlighted that the conditions and the level of service delivery in townships were degrading and municipalities did not have adequate financial muscles. CoGHSTA introduced the integrated development planning process in their endeavour to improve planning at local level. The discourse on governance and planning internationally is centred on integration, performance management and participation (RSA, 1998).

Local government is the key agent in transforming and democratizing development in South Africa (Parnell et al. 2002). As Rauch (2003) showed, to mandate grassroots development and public participation, integrated development planning should be used as the vehicle. Physically, local government is the closest to the community: therefore it is expected that opportunities to facilitate development and engage directly with local people in a local sphere should be created by municipalities rather than by other spheres of government (Ceasar and Theron, 1999; Chapter 7 of The Constitution of the Republic of South Africa (1996)). Chapter 5 of the Municipal Systems Act (MSA) (2000) consists of four parts, detailing the general matters pertaining to IDPs; contents of IDPs; process for planning, drafting, adopting and reviewing IDPs; and the miscellaneous features of IDPs, which include effecting the IDP and the status of the IDP. Importantly, part two of Chapter 5 in the MSA (2000) outlines several core components of IDPs which provide a yardstick for municipal integrated planning.

South African local authorities use integrated development planning as a method to plan future development in their areas principally because rural areas were left undeveloped and largely un-serviced. As much as the IDP was a contextual response to challenges facing the post-apartheid government - in particular, the need to gets a new system of local government working. The National Department of Cooperative Governance (DCoG) adopted good practices from other countries to improve governance at local government level. Municipal planning for service rendering in South Africa is a compulsory process for all municipalities in terms of section 25 of the Municipal Systems Act, 2000. The main objective of this planning initiative is to ensure that, current service delivery challenges are met by examining relevant modern systems and joint venture approaches so that municipalities perform their functions diligently and in a way that is developmental and fiscally responsive.

According to The IDP Guide-Pack (DPLG - 1999/2004), integrated development planning provides a process though which municipalities prepare strategic development plans for a five year period. It is a principal strategic planning instrument which guides and informs all planning, budgeting, management and decision-making in a municipality. Furthermore, it is a legislative requirement that an IDP be seen as the primary blanket plan which takes precedence over all other plans which guide development regarding municipal planning (Naude, 2002). Harrison (2003) pointed out that the IDP was a contextual response to challenges facing the post-apartheid government - in particular, the need to get a new system of local government working - but the nature and form of the IDP were strongly circumscribed by the international discourse and practice which prevailed at the time of its introduction and early development. Phago (2006) argues that although developing an IDP is a legislative requirement as well as standard practice for municipalities in South Africa, prescriptions on its content or specifications are not provided. Each municipality is responsible and accountable for its planning process (Craythorne, 2003).

As such, a municipal IDP should be a clear manifestation of prioritized communal needs that require urgent attention from the local government. As a style of strategic planning that departs from the master planning models of the past, the preparation of IDPs represents a more flexible model for responding to the many challenges that face local 
authorities. IDPs are local planning processes that are intended to give strategic direction to the work of municipalities (their programmes, projects and budgets) and to activities undertaken by provincial and national government departments operating in their areas. It is an approach to planning that involves the entire municipality and its citizens in finding the best solutions to achieve good long-term development. It represents an opportunity to forge a stronger relationship between planning and implementation, which can be argued, that planners have generally been weak at achieving in the past.

As stated in the IDP for the Capricorn District Municipality (2011), IDP is a comprehensive, integrated and multifaceted plan that:

- links, integrates and co-ordinates the functions and strategies of a municipality;

- aligns the resources of a municipality with the agreed-upon objectives and outcomes;

- forms the overall strategic plan for the municipality; and

- is a mechanism for participation and democratization of local government

The core components of development planning are in compliance with the constitutional mandates of local government which are to ensure the provision of services to communities, to strengthen democratic values at local municipality level and to encourage the involvement of communities, including the marginalized groups (RSA, 1996). The IDP as a strategic tool guides the formulation, implementation and execution of strategies including the effective use of scarce resources by focusing on the most important needs of local communities to speed up service delivery to the poorest of the poor. It should also ensure the empowerment of local communities in local economic development, as outlined in section 152(1) of the Constitution of the Republic of South Africa, 1996 (RSA, 1996).

Todaro et al. (2009) posits that the planning process can be described as an exercise in which a government first chooses social objectives, then sets various targets and finally organizes a framework for implementing, coordinating and monitoring a development plan. They rightly argued that the economic value of a development plan depends to a great extent on the quality and reliability of the statistical data on which it is based. When these data are weak, unreliable or non-existent, the accuracy and internal consistency of economy-wide quantitative plans are greatly diminished. Thus, IDPs are designed to act as a vehicle which will facilitate development within municipal areas. This has also created expectations from local communities that the state has to provide employment. As such this lack of understanding of what the IDP seeks to achieve has not allowed communities to exploit the available resources to create self-employment and become self-reliant.

Marais, Human and Botes (2008) argued that the IDPs fail to achieve their objectives precisely because they do not use development indicators as a basis on which their strategic decisions are made when monitoring their programmes or projects. Measurable indicators are not identified during the IDP process and thus making it difficult if not impossible to determine the level of success of the IDPs. Their absence and the impact they have on the effectiveness of the IDPs needs a thorough analysis. Secondly, Chapter 4 of the MSA of 2000 requires that municipalities in preparation and reviewing of their IDPs should encourage participation and it further indicates clearly how the development of community participation should unfold. A municipality must develop a culture of municipal governance that complements formal representative government with a system of participatory governance. The constitutional mandate of local government is to ensure the involvement of communities in the IDP process (RSA, 1996).

Marais, et al., (2008) pointed out that the use of development indicators has shifted from focusing on economic indicators to indicators attempting to measure sustainable development. It was during the 1990s that the United Nations Development Programme (UNDP) developed the Human Development Index (HDI) to measure the average achievements of a country in three basic dimensions of human development: a long and healthy life, as measured by life expectancy at birth, knowledge, as measured by the adult literacy rate and the combined primary, secondary and tertiary gross enrolment ratio and a decent standard of living, as measured by the GDP per capita (PPP US\$) (Todaro et al., 2009). Other indicators, such as the Gender Equality Index (GEI), which measures the inequalities in attainments of human development indicators between females and males, the Human Poverty Index (HPI) captures deprivation in three dimensions of human development, namely, economic, education and health. GDP which directly captures the economic attainments and hence the level of well-being of individuals and the Gini coefficient which is normally used to measure inequality in wealth, were also developed. The high value of the Gini coefficient (0.69) in South Africa illustrates the skewed development the country finds itself in.

The use of development indicators in planning is not only required by legislation (in terms of MSA, 2000 among others), but also ensures accountability by decision-makers when measuring development indicators (Mukherjee, 1981; Parnell and Poyser, 2002; and Marais, et al., 2008). The level of development in municipalities is informed by development indicators which guide municipalities where scarce resources should be allocated. However, it has to be 
stressed that any indicator is only as good as the data upon which it is built. The strengths and weakness of indicators lie in their selection, which facilitates decision-making but also opens the door to data manipulation. Data sets can be of poor quality or of good quality and there may be gaps. Indicators are needed to increase focus on development and assist decision-makers at all levels to adopt sound national sustainable development policies.

The Performance Monitoring and Evaluation (PME) unit (RSA, 2007) points out that development indicators provide a framework to present aggregate data on human development and provide evidence-based pointers to the evolution of society. Indicators are seen as tools for guiding public policy and programmes towards the development goals of the society and at the same time provide criteria to evaluate the process of social change. The PME unit (RSA, 2007) considers indicators as markers that help define the milestones in a journey of social change. An indicator can be compared to a road sign which shows whether you are on the right road, how far you have travelled and how far you have to travel to reach your destination.

Municipalities in South Africa are the main implementation agencies for government policies and programmes in the country and their developmental obligations have been clearly spelt out in various policy documents (SA- DPLG 2001a). CoGTA has provided municipalities with extensive prescriptions and guidelines to implement performance assessments as part of their statutory obligations regarding integrated development planning in the local government sphere (DPLG 2001a, 2001b, 2003). CoGTA's Municipal Planning and Performance Management Regulations (2001) require that a "municipality must set key performance indicators, including input, output and impact indicators, in respect of each of the development priorities and objectives " that it must specify in terms of the Local Government's Municipal Systems Act, 2000 (SA - DPLG 2001c).

According to Marais et al. (2008), baseline indicators are needed to develop targets in order to measure the progress made towards achieving the set goals. Development indicators have three functions: to monitor change, to measure social, economic and environmental welfare, and, lastly, to provide comparisons based on targets, benchmarks or performance in the past (Schwabe, 2002). Indicators measure the impact of development and intervention programmes as well as performance of implementing agencies and those of government. In terms of monitoring progress, indicators perform two major functions. Firstly, they describe a baseline situation of various components of the development process. Secondly, they measure change in baseline information or data within a temporal and spatial context (Statistics South Africa, Framework for Policy, Information and Planning, 2006). It is necessary to pre-define change in the desired outcomes by way of setting goals for a specific period of time as a way to increase indicator effectiveness (Achkbache, et al., 2001).

\section{Challenges and Problems with Regard to Development Indicators}

There are serious challenges with regard to development indicators which relate to their quality assurance as well as their validity, relevance, measurability, efficiency, simplicity, availability and representativeness of indicators. Indicators are critical for policy and decision-making and their relevance is important (IISD, 1998; OECD, 1999). Indicators are mostly dependent on quantitative data and since collecting information is costly, the collection of relevant data is essential, since the analysis of unreliable or biased data could result in serious distorted analytical and policy conclusions (Parnell and Poyser, 2002). The coherence of statistical information which would reflect the degree to which it can be successfully brought together with other statistical information within a broad analytical framework could be a daunting task for a developing country like South Africa. The use of standardized concepts, classifications and target populations could promote coherence, as does the use of a common methodology across surveys. Cross-checking and validating data from different statistically agencies on the same information will minimize the challenges of bias.

Complications with the use of indicators include the fact that it is difficult to develop indicators that are applicable to diverse contexts, there are many ideological and other normative obstacles that have to be overcome, and the validity of indicators to measure exactly what is intended to be measured, is not always accepted in different schools of thought on this matter (UNDP 1997, UN-CSD 2001, World Bank 2001). Cloete (2004) argued that there is a general lack of sufficient, reliable data to use for measurement purposes, as well as a lack of appropriate information management and assessment of systems to record, manipulate and convert these required data sets into the desired indicator formats. In general, there is also a high risk of unnecessary duplication when determining measuring instruments because of high degrees of ignorance about what is already available and what is not.

\section{Materials and Method}

The research design used for this article was qualitative in nature in which a structured questionnaire was administered 
as a tool for data collection. IDP documents of sampled municipalities were also obtained and analysed.

The population of the study was the four local municipalities and the Capricorn District Municipality. Each municipality has its own IDP. Local municipalities are constituted by rural and semi-urban municipalities. A sample is a group of elements drawn from the population, which is considered to be representative of the population, which is studied in order to acquire some knowledge about the entire population and therefore sampling is the technique by which a sample is drawn from the population (Bless et al., 2000). The study used a non-probability sampling method in the form of purposive sampling. De Vos et al. (2004) indicate that this type of sample is based entirely on the judgement of the researcher, because a sample is composed of the elements that contain the most characteristics, representative or typical attributes of a population. A sample of four municipalities was obtained and within them, the interviews focused on the mayor or the speaker of the selected municipality; IDP manager, municipal IDP official within the selected municipalities, who are directly involved with the development of the IDP process; traditional authority representative from the community within the municipality; a group of ten (10) youths who might have a different perspective as well as groups of ten (10) people from Community-Based Organizations (CBOs) such as business and women's groups. Qualitative analysis is a non-numerical examination and interpretation of observation, for the purpose of discovering underlying meanings and patterns of relationships (Babbie \& Mouton, 2006).

Data were collected, validated and analysed using a thematic approach data were analysed. As such, different data were grouped together as per issues picked up during data collection.

\section{Results and Discussion}

Findings from the assessment report of municipal IDPs: The Member of the Executive Committee's (MEC's) 2011/12 IDP assessment report revealed that all municipalities within Capricorn district demonstrated compliance with the legal framework as prescribed by government, by adopting their IDPs for the 2010/11 financial year. The credibility of these IDP documents were then rated by the MEC for CoGHSTA after undergoing assessment and the results showed that only two local municipalities (Aganang and Lepelle-Nkumpi) within Capricorn district received a high rating, implying that their IDPs were credible. This constitutes only $40 \%$ of the entire district excluding the district municipality. Capricorn District Municipality also received a high rating. The other three remaining municipalities received medium ratings.

Existence of development indicators: The use of development indicators is mandatory in the IDP as they ensure the use of measurement for policy and decision-making. Indicators ensure that the deployment of scarce resources is channelled to areas of dire need as alluded to in the literature. The analysis of IDP documents of the Capricorn district family of municipalities reveals that some indicators do exist despite being single indicators. Single indicators consist of a single variable. It however, emerged from the interviews that officials were using these indicators without any clear understanding of how they should address issues of development in their municipalities. There are certain drawbacks attached to the use of these indicators and these should be taken into account when considering which ones to use. The quality of the data produced by different agencies differs due to varying methods of data collection, different concepts and standards and single indicator cannot capture all the important aspects of development. No matter how difficult this may be, it is imperative that focus be maintained in terms of measuring social progress or improvements in the quality of life, for the purpose of proper planning (IISD, 1998; OECD, 1999).

Findings from the analysis of municipal IDPs: Planning is not complete without the effective utilization of indicators. The use of indicators in the context of planning induces a source of social change. It has however been observed that data was presented in a fragmented manner across all the IDP documents of the municipalities under study. All the IDP documents of the five local municipalities and one district municipality were analysed regarding which indicators they are using and also their horizontal and vertical alignment with neighbouring municipalities, provincial government indicators, the Compendium of National Indicators and Millennium Development Goals (MDGs) indicators. Municipalities do not have a compendium of development indicators common across all municipalities in the district. A total of 72 indicators were identified in all these municipalities within Capricorn District such as the proportion of people in a household without a pit latrine with ventilation or flush toilet, people living in a shack, People aged 15-65 who are unemployed, and so forth.

In terms of indicator usage, Capricorn District Municipality (CDM) used more indicators than its local municipalities. Molemole Municipality (50\%) has used exactly half of the total indicators and is the highest, compared to other local municipalities, in terms of indicator usage within the Capricorn District, followed by Polokwane Municipality with $47 \%$. Blouberg has the least (22\%) number of these indicators. Most of these indicators in the IDPs are target indicators without baseline indicators and as a result, making it difficult to measure if there was indeed progress. Access to a range of different data sets as alluded to by Boyne (2003), makes it possible to compare performance change, as measured by 
these indicators and services delivered. Whether these indicators, either singularly or in aggregate, give a reliable measure of improvement is of course a different matter.

Gaps within the current indicators: All municipalities have challenges in using target indicators without baseline indicators. The development of targets depends solely on the availability and existence of baseline indicators. Some municipalities provided target indicators without baseline indicators in place. For example, with regard to HIV infection rates, some municipalities only indicated that the infection rate should be reduced by $20 \%$, a target which is not measurable and unattainable in the absence of baseline information. All indicators presented in the IDP documents were single indicators with no attempt being made to include composite indicators such as Human Poverty Index (HPI). It should be acknowledged that a single indicator cannot cover all the important aspects of development. Composite indicators can also be too abstract and pose a serious challenge when drawing comparisons between individuals or households and they also have limitations in providing adverse gender or race disparities on social progress (May et al., 2000). A case in point is that of the Gini coefficient which measures inequality in a population regarding a specific value but does not measure disparities in terms of asset distribution and ownership and also that it assesses income only and does not show gender. Development indicators form the basis of integrated development planning. The inadequate usage of development indicators in the IDPs has serious implications for development planning.

Time-series data: The other observation was that not all of these municipalities under study were consistently using more than one data points. There are instances where planners in these municipalities used two to three variables. This could be a deliberate effort by the IDP managers to conceal those areas in which they are not performing well. A properly constructed set of indicators may not only suggest the planning measures which should be employed but also throw light on a better formulation of targets, goals and even the objective of planning (Mukherjee, 1981). The efficiency of use of indicators for planning may not be fully realized because of the manner in which IDP managers are often found to employ indicators to satisfy their own machination.

Benchmarking municipal performance: Benchmarking is the process of identifying "best practice" in relation to both products and the processes by which those products are created and delivered. It involves looking outward to examine how others achieve their performance levels and to understand the processes they use. All sampled municipalities in Capricorn district do not benchmark their performance. Blouberg had at least benchmarked on one variable, demographic profile, while the other four municipalities never attempted to benchmark. This could be seen as an acknowledgement of complacency by municipalities since no effort was being put to be competitive in the way they conduct their business.

Alignment of municipal IDPs with the Provincial Strategy: Firstly, the Limpopo's five year strategy (2010 to 2015), the Limpopo Employment, Growth and Development Plan (LEGDP), identified mining, agriculture, tourism and manufacturing as key drivers of the economy in the province but none of these sectors find resonance in any of the strategic plans of these municipalities. Municipalities such as Aganang, Molemole and Blouberg, have vast areas for farming and could at least have identified agriculture as a key driver of their economy and could have included some indicators related to the sector. Secondly, given the rural and semi-urban nature of these municipalities, they are without any doubt affected by brown environmental problems such as smelling pit latrines, exposure to polluted air caused by paraffin stoves they use for cooking and burning of disposed refuse; but ironically, there were no indicators and strategies developed to deal with these challenges.

Findings from the interviews on development indicators used in planning: The development of an IDP document is the responsibility of the IDP managers and other officials in the IDP office as well as some councillors within a municipality. Although the municipal manager is accountable, the IDP manager remains the custodian of the document. The CBOs, traditional authorities and the youth were not very clear with legislative frameworks but only knew that they have to form, at some point, part of the IDP process. How indicators should be used in the process was foreign to them.

All municipalities in Capricorn district comply with the legislative framework in terms of adopting their IDPs and involving communities in the IDP process. It has also been established that some municipalities are experiencing challenges with regard to development planning. Firstly, there is limited knowledge and skill amongst officials, both in utilizing development indicators in planning and how to analyse the information. Secondly, there is lack of or unavailability of recent disaggregated, lower-level data to populate municipal indicator matrices. Municipalities' reliance on free census data, which has a five year cycle, could be an impediment to their indicator usage since indicators from other data sources or statistical agencies come at an exorbitant price. National statistics from sector departments such as health, education, agriculture, and so forth, are available at local level and are often ignored. Economic indicators such as the Gross Geographic Product (GGP) can only be disaggregated at the level of a province by Stats SA and therefore municipalities acquire those indicators from other statistical agencies at a cost.

Benchmark indicators measure project progress towards development objectives and result in more meaningful 
project monitoring and evaluation by municipalities. There was absolutely no attempt by Municipalities to horizontally benchmark their achievements with that of neighbouring municipalities or municipalities in the same category in almost all indicators or vertically with provincial and national averages in some indicators. Kiregyera (2005) argues that the consequences of this include: poor issue identification, policy analysis and design; uninformed and occasionally costly decision-making; inability to properly monitor implementation of policies, projects and programmes as well as inability to evaluate their success. Little use was made of baseline indicators to measure the effectiveness and efficiency of programmes or projects.

There is a general lack of sufficient, reliable data to use for measurement purposes, as well as a lack of appropriate information management and assessment systems to record, manipulate and convert these required data sets into the desired indicator formats. Where data exist, its integrity is frequently suspected. The government should begin to promote synchronization of data across sectors and levels of government - as Kiregyera (2005) argues, this will assist the government to focus on performance and reporting on the achievement of outputs, outcomes and impact, using information to improve decision-making and steer country-led development processes towards clearly defined development goals.

\section{Case by Case Analysis of Service Provision by Municipality}

Aganang Municipality: This municipality is $100 \%$ rural without a proper revenue base. During the interview with different respondents within the Aganang municipality, they almost all answered in the same way with regards to the provision of basic services such as access to water, electricity, sanitation, refuse removal and free basic services. They showed satisfaction on a number of services provided by the municipality. The youth could not respond adequately to questions on the number of people who have access to social grants, but they in principle agreed on their existence. Traditional authorities have profiles of the household members and are as a result glued to activities within their authority.

When the IDP manager was asked about what should be done to ensure the effectiveness of the IDP in the provision of services, he opined, "the municipality should establish a centre for development programmes. It is this centre where capacity building will take place". This echoed the sentiments of the traditional authority representative as well as the youth who argued that there should be funds set aside every five years to capacitate the community members. The IDP manager, a municipal official dealing with IDP documentation and the mayor suggested that indicators should be in line with Key Performance Areas (KPAs). In other words, there should be indicators for every KPA and these should find expression in the Service Delivery and Budget Implementation Plan (SDBIP). Most respondents, community members (traditional authority and the youth) particularly blame the inadequacy of resources as hindering development in their areas. The mayor spoke emphatically about monitoring and evaluation systems within the municipality as not good enough to put an eagle's eye on the projects and programmes that are being implemented.

Responses from the community members are an indicator of their satisfaction with the provision of basic services in the Aganang Municipality. Many of the respondents are ambivalent (neither satisfied nor dissatisfied) with the provision of water as compared to a few who are satisfied. Only the IDP manager and the mayor are the ones who were satisfied with the services reflecting an element of bias as they are the bonafide custodians of the IDP. The mayor acknowledged that there is still a lot to be done when it comes to the provision of water. The communities are very satisfied with the provision of electricity and to some extent with social grants. However, the mayor, the IDP manager, a municipal official and the youths are not satisfied with social grants. The CBOs group expressed much dissatisfaction with refuse removal citing pollution as a major concern. The respondents affirmed that although access to electricity was not reliable especially during thunderstorms, the time it takes for the municipality to attend to faults has improved.

Molemole Municipality: This municipality is a rural municipality with little tax revenue. The municipality relies heavily on the small town of Mogwadi which has a tax base. All the respondents from the Molemole municipality were "singing from the same hymn book" when it comes to delivery of services. The IDP manager, the municipal official, the mayor, the CBO representatives, and the youth representatives were very satisfied with access to water by households whereas only the traditional authority representative was dissatisfied.

Blouberg Municipality: The rural nature of the municipality poses challenges with regard to the provision of services. The problem can be traced back to the apartheid era. With regard to access to social grant, the youths and the $\mathrm{CBOs}$, were generally dissatisfied. This shows that service delivery still has to overcome a number of challenges to fully realize its aims and objectives to service the entire population within the given jurisdictions. The respondents showed a high satisfaction level with regard to the provision of electricity.

Lepelle-Nkumpi Municipality: The community members of the Lepelle-Nkumpi municipality were not satisfied with refuse removal and access to social grants claiming that services were only provided to those communities in 
townships. There were also concerns with the provision of sanitation by the municipality. Again this could be the result of the rural nature of the municipality, particularly the many rural villages located within the jurisdiction of the municipality.

Polokwane Municipality; Polokwane municipality comprises of the town Polokwane with a number of suburbs, simplexes and complexes, more than a handful of townships and rural villages. It is in the hub of business in Limpopo. It has a larger revenue base than any of the four other local municipalities within the Capricorn District Municipality. The provision of services was high on their agenda as there is a general level of satisfaction with basic services by communities within Polokwane municipality. This was encouraging except with regard to social grant as the mayor, the traditional authority representative, the $\mathrm{CBO}$ group and the youth representatives were dissatisfied with the manner in which the South African Social Security Agency (SASSA) deals with applications as the aged have to apply over and over again as their application forms got lost. The respondents showed a high satisfaction level with regard to the provision of electricity.

\section{Model for Data Collection and Processing for Municipalities}

This model suggests that for effective use of indicators and available data, municipalities must follow the following procedures/processes as enshrined in the model below (see Fig 1).

The first step includes the collection of primary and secondary depending on the data imperatives and capacity of the municipality. From these data, single indicators are generated. From single indicators, aggregate/composite indicators are then formulated. It is at this stage that a compendium of agreed upon indicators (baseline) are selected for monitoring through stakeholder consultation and consensus. Baselines are established at this stage. Trends and patterns are established using time series analysis. Comparisons are then made against established benchmarks from equivalent size municipalities or national of provincial benchmarks. Assessment and interpretation of the data as well as results feed into the monitoring and evaluation system.

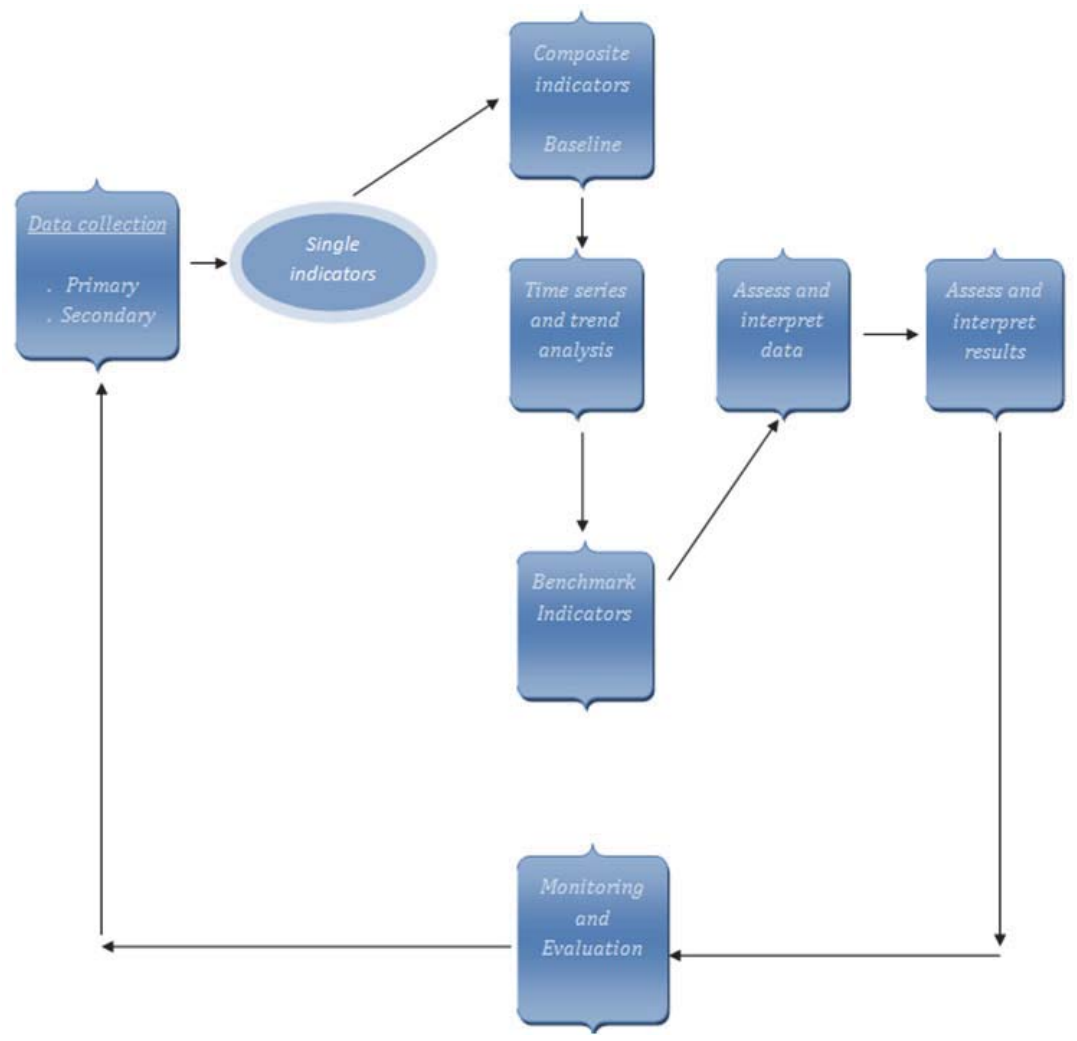

Figure 1: Model for data collection and processing for municipalities 


\section{Conclusion}

The aim of the study was to investigate the effectiveness of the IDP document in the family of municipalities within the Capricorn District Municipality in the Limpopo Province. The study focused on the use of development indicators as performance areas that affect service delivery and can cause community disillusionment. Planners should not be daunted by the intricacy of development indicators, as they should only focus only on those that are being used for planning provided by government. Given the wide range of development indicators, only a handful is presented in the municipalities IDPs. Even in case where those limited indicators were provided, the focus was more on social services and infrastructure. The agricultural sector is supposed to be the driver of the economy, particularly in Blouberg, Molemole and Aganang Municipalities, but the conspicuous absence of indicators on this sector is of great concern.

It is quite apparent from the above analysis that the use of development indicators in the IDPs is limited to guiding policy intervention. Their usage should be supported by the appointment of qualified employees with the requisite skill to implement the legislative requirements. Political interference in the appointment of employees who do not possess the requisite skill to do data analysis only compounds the problem which municipalities are having and promotes institutional mediocrity.

\section{Recommendations}

Firstly, IDP officials at municipalities, who generally lack the skill to analyse data, should be provided with training in the analysis of development indicators. A critical challenge for municipalities as raised by CBOs and the youths, common in all municipalities, is how the appointment of staff can be insulated from political interference. A rudimentary understanding of terms such as mean / average, standard deviation, standard errors, graphical displays and so forth, put in a non-statistical manner and then the interpretation of and assessment of data might assist municipalities. The next step will involve the interpretation and assessment of actual results.

Secondly, municipalities should ensure effectiveness and efficiency of the training and capacity building programmes by addressing the weaknesses or constraining factors. One of the main reasons for the failure of IDPs is the lack of commitment and project management skills among municipal officials as it was evident in their lack of forward planning with respect to the Municipal Infrastructure grant (MIG).

Thirdly, for municipalities to be able to address challenges with regard to baseline information, they should either conduct a local study; use administrative records or commission a study. The use of Community Development Workers (CDWs) to profile their wards could go a long way in addressing this problem as they are at times bound to purchase data from independent statistical agencies when census data are not available or are not recent. The establishment of research units or data management units with requisite skills can also assist municipalities in doing annual projections.

Fourthly, the Department of Cooperative Governance, Human Settlement and Traditional Affairs (CoGHSTA) and/or the South African Local Government Association (SALGA) should collectively develop a compendium of municipal development indicators and then ensure that these indicators appear in every municipality's IDP document in the province.

Lastly, it is critical that the IDP is aligned to the Service Delivery and Budget Implementation Plan (SDBIP) or the SDBIP finds resonance in the IDP. This will ensure that the monthly revenue and expenditure projections, quarterly service delivery targets and performance indicators of the SDBIP are compared and adapted (if necessary) to ensure alignment with the strategic thrusts, key performance activities, key performance indicators, and actual programmes and projects of the IDP.

\section{References}

Achkbache, B., Belkinas, M., Dink, m., Eele, G. and Swanson, E.2001. Strengthening statistical systems for poverty reduction strategies. Sourcebook for Poverty Reduction Strategies. Washington, D.C.: World Bank.

Babbie, E. and Mouton, J. 2006. The practice of social research. Cape Town South Africa. Oxford University Press.

Bless, C. and Higson-Smith, C.H. 2000. Fundamentals of Social Research Methods. Cape Town. Juta.

Boyne, G.A. 2003. 'What is Public Service Improvement'. Public Administration, 81, 2.

Ceasar, N. and Theron, F. 1999. Assessing Attitudes and Perceptions on IDP - The case of Stellenbosch. Administration Publica, 9(2).

Cloete, F. 2004. Measuring Sustainable Governmental Performance. Journal of Public Administration. Vol 39. No.4.December 2004.

Craythorne, C.L. 2003. Municipal Administration. $5^{\text {th }}$ edition. Cape Town: Juta.

Democratizing Local Government: The South African experiment. Cape Town: UCT Press. Pp. 251-261.

Department of Provincial and Local Government (DPLG) 2002. IDP Guide-Pack. Volume III: Methodology. Pretoria: Government printers 
Department of Provincial and Local Government (DPLG). 2001. IDP Guide Pack, Guide iv, Toolbox. Pretoria:Formeset Printers and Cape Ltd.

Department of Provincial and Local Government Affairs.1999/2000.Integrated Development Planning Guide-Pack: A General Overview. Pretoria: Government Printers.

Development (IISD). 1998. City of Winnipeg quality of life indicators, IISD,Canada: Winnipeg. [Online] Available: www.iisd.org. January 1998.

De Vos, A.S., Delport, C.S.L., \& Strydom, H. 2005. Research at Grass roots. Pretoria: Van Schaik.

Harrison, P. 2003. Towards integrated inter-governmental planning in South Africa: The IDP as a building block. Report prepared for DPLG and Municipal Demarcations Board International Institute for Sustainable

International Institute for Sustainable Development (IISD). 1998. City of Winnipeg quality of life indicators. IISD, Canada:Winnipeg. [Online] Available: www.iisd.org.

Kiregyera, B. 2005. A case and some actions for improving statistical advocacy in Poor Developing Countries. African Statistical Journal. Vol.1-3

Kriege, S. 1998.Proposing a transdisciplinary programme in urban development and management for the University of the Orange Free State, South Africa. Finalreport. Unpublished dissertation, Institute of Housing and Urban Development Studies, Rotterdam.

Marais, L., Human, F. and Botes, L. 2008. Measuring what? The utilization of development indicators in the Integrated Development Planning Process. Journal of Public Administration. Vol.43. No.3. September 2008.

May, J. Woolard, I. and Klasen, S. 2000. The nature and measurement of poverty and inequality. In May, J. (ed). 2000. Poverty and inequality in South Africa: Meeting the challenge. Cape Town: David Phillip

Mukherjee, R. 1981. Use of social indicators in planning. In UNESCO, Socio economic indicators for planning: Methodological aspect and selectedexamples, Socio-Economic Studies 2. Paris: UNESCO, pp. 11-21.

Naude, C. 2002. IDP is a Blanket Plan. Pretoria: CSIR.

Parnell, S., \& Poyser, M. 2002. The value of indicators as a tool for local government. In Parnell, S., Pieterse, E, Swilling, M., \& Wooldridge, D. (eds.).

Phago, K.G. 2006. The IDP in South African Local Government: Consolidating Service Delivery within the City of Tshwane Metropolitan Municipality. Pretoria.

Rauch, T.R. (ed.). 2003. Principles of integrated development planning and assessment of the 2001-2002. Decentralized Development Planning Task Team.

Schwabe, C.A. 2002. Information: The foundation of sustainable development. HSRC. http:///www.hsrcpress.ac.za

Todaro, P.M. and Smith, S.C. (2009) $10^{\text {th }}$ ed. Economic Development. Pearson Education Pte. Ltd. India

RSA. 1995b. Development Facilitation Act No. 67 of 1995. Pretoria. Government Printers

RSA. 1996. The Constitution of the Republic of South Africa, No. 108 of 1996.

RSA. 1998. White paper on Local Government. [Online] Available: www.policy.org.za/html/govdocs/white papers.

RSA. 2000. Local Government: Municipal Systems Act, Act No. 32. Government Gazette, Vol. 425, No. 21776, 20 November 2000.

RSA. 2002. Department of Provincial and Local Government (DPLG). 2002. IDP Guide Pack, Guide IV, Toolbox. Formerset Printers Cape (Pty). Ltd.

Un-CSD. 2001. Indicators for Sustainable Development, UN Commission for Sustainable Development, New York.

UNDP. 1997. Human Development Report 1997, Oxford University Press, New York.

SA-DPLG. 2001a. Performance Management Guide for Municipalities, Department of Provincial and Local Government, Pretoria. (http://www.dplg.gov.za/Documents/AnnualReports/Reports/pm.pdf,25 April 2003).

SA-DPLG. 2001b. Municipal Planning and Performance Management Regulations, 2001. (Regulation No. 7146 in Government Notice R796 of 24 August 2001, promulgated by the

Department of Provincial and Local Government Gazette No. 22605), Government Printer, Pretoria.

World Bank. 2001. World Development Indicators 2000, World Bank, Washington, DC. 